\title{
CARDIOVASCULAR MEDICINE
}

\section{Long QTc predicts future cardiac death in stroke survivors}

\author{
K Y K Wong, R S Mac Walter, D Douglas, H W Fraser, S A Ogston, A D Struthers
}

Heart 2003;89:377-381

See end of article for authors' affiliations

Correspondence to

Dr Kenneth Wong,

Departments of Clinical Pharmacology and

Therapeutics, University of

Dundee Medical School,

Ninewells Hospital,

Dundee DDI 9SY, UK.

kywong@doctors.org.uk

Accepted

20 November 2002
Objectives: To test the hypothesis that the QTc of any lead of the ECG predicts death after stroke, and to determine which lead of the ECG carries the greatest risk of cardiac death when its QTc is measured. Design: Standard 12 lead ECGs were analysed by one observer who was blind to patient outcome. Setting: A major teaching hospital in Scotland.

Patients: 404 stroke survivors were studied at approximately one year after the cerebrovascular event and followed for up to 6.3 years.

Outcome measures: Death from any cause and cardiac mortality.

Results: The QTc measured from any lead of the ECG (except aVR) was associated with death from any cause. A prolonged QTc in limb lead III and chest lead V6 carried the highest relative risk of cardiac death (a 3.1-fold incease). After adjusting for overt ischaemic heart disease, pulse pressure, glucose, and cholesterol, a prolonged QTc in lead V6 was associated with a relative risk of cardiac death of $2.8(95 \%$ confidence interval $(\mathrm{Cl}) 1.1$ to 7.3$)(p=0.028)$ and of death from all causes of $2.9(95 \%$ $\mathrm{Cl} 1.6$ to 5.3) ( $p<0.001)$. If the QTc in V6 exceeded $480 \mathrm{~ms}$, then the specificity of predicting cardiac death within five years after the stroke was $94 \%$.

Conclusions: Although treatment of the conventional modifiable risk factors is important, stroke survivors with a prolonged QTc in lead V6 are still at a high risk of cardiac death and may need more intensive investigations and treatments than are currently routine practice. l $\mathrm{n}$ patients who have a stroke, the initial stroke is the main cause of death in the first 30 days. After the first year, nonstroke cardiovascular disease becomes the most common cause of death. ${ }^{1}$ If those patients at highest risk of impending non-stroke cardiovascular death could be identified then it might be possible to intervene to prevent or delay this event.

There has been much recent interest in the measurement of QT dispersion (maximum - minimum QT) from the ECG. This is because it appears in some $e^{2-6}$ but not all ${ }^{7}$ studies to be able to predict cardiac death. Recently, it was shown that a prolonged maximum heart rate corrected QT interval (QTc max) was actually better than the QTc dispersion at predicting cardiac death in non-insulin dependent diabetic patients. ${ }^{8}$ We therefore applied this technique in a large group of stroke patients to see if QT interval analysis could identify those who make a good recovery from their stroke only to succumb later from a non-stroke cardiac death. We compared QT interval analysis with other conventional risk factors such as pulse pressure, to see if it added to the risk assessment already available from the conventional factors.

Our study also addressed a second question. Despite the wealth of evidence linking long QT dispersion to cardiac death, methodological concerns have hampered QT analysis. The major problem is that it is not always easy to define where flat $\mathrm{T}$ waves end, and crucially such difficulties in defining the end of the T wave are multiplied when the QT interval has to be calculated for 12 different ECG leads to work out QT dispersion or QTc max. Another concern is that it is very time consuming to calculate QT dispersion or QTc max, and this drawback may not be overcome by the use of automated techniques as they often give discrepant results. ${ }^{9}$ In an attempt to get round this problem, we tested the hypothesis that QTc of any single lead of the ECG might predict cardiac death. We also investigated which lead of the ECG with a prolonged QTc carries the greatest risk of cardiac death and death from all causes.

\section{METHODS}

Patients

We studied 404 patients in sinus rhythm who attended the stroke follow up clinic between 1989 and 1992. These stroke patients were recorded in the Dundee stroke project database register as previously described. ${ }^{10}$ The Tayside committee on medical research ethics raised no objection to our study. Procedures followed were in accordance with institutional guidelines. The study complied with the Declaration of Helsinki.

\section{Procedures}

The median time of the initial visit was one year after the stroke (minimum 0.2 year). ECGs were done at this initial visit. Patients who had atrial fibrillation or flutter, bigeminy, paced rhythm, or bundle branch block were excluded because these ECG changes would make the QT interval difficult to measure reliably. In addition, atrial fibrillation is a well known risk factor for cardiac death, and we were trying to determine the prognostic factors in the majority of stroke patients who are in sinus rhythm.

The ECGs were analysed by one individual who was blinded to patient outcome. QT interval analyses were done by digitising the ECGs. The technique that we used for digitising the ECGs was first described in 1994. ${ }^{5}$ The QT interval was defined as the time period between the onset of the QRS complex and the end of the $\mathrm{T}$ wave (when the $\mathrm{T}$ wave returned to the isoelectric line). If the $\mathrm{T}$ wave was followed by a $\mathrm{U}$ wave, then the nadir between the $\mathrm{T}$ and the $\mathrm{U}$ wave (that is, the lowest point of the curve) would be taken as the point where the T wave ended. The heart rate corrected QT interval (QTc) was defined as the QT interval divided by the square root of the RR interval (Bazett's formula). The QTc max was defined as the maximum QTc measured from a 12 lead ECG. In the vast majority of ECGs, it was possible to work out the QTc of all 12 leads $(83.4 \%)$. The mean (SD) number of leads that were digitisable in this cohort of patients was $11.8(0.45)$, range 9-12; $0.5 \%$ had nine digitisable leads, $1 \%$ had $10,15.1 \%$ had 11 ).

The patients were followed for up to 6.3 years thereafter. The certified cause of death was obtained by record linkage with data from the registrar general in Scotland. The accuracy of this dataset has been shown previously to be $98 \% .^{11}$ Total mortality and cardiac death were the primary end points 
Table 1 Unadjusted relative risks of prolonged QTc in any single lead of the ECG

\begin{tabular}{|c|c|c|c|c|}
\hline \multirow[b]{2}{*}{ QTc } & \multicolumn{2}{|c|}{ Death from all causes } & \multicolumn{2}{|l|}{ Cardiac death } \\
\hline & $\operatorname{RR}(95 \% \mathrm{Cl}) \dagger$ & $p$ Value & RR $(95 \% \mathrm{Cl}) \dagger$ & $p$ Value \\
\hline I & 2.1 (1.3 to 3.6$)$ & $0.005^{*}$ & $2.2(0.93$ to 5.2$)$ & 0.074 \\
\hline II & 2.2 (1.3 to 3.8 ) & $0.002^{*}$ & 2.6 (1.1 to 6.2 ) & $0.028 *$ \\
\hline III & 1.8 (1.1 to 3.2$)$ & $0.029 *$ & 3.1 (1.3 to 7.4$)$ & $0.010 *$ \\
\hline $\mathrm{aVR}$ & $1.6(0.96$ to 2.8$)$ & 0.072 & $2.0(0.83$ to 4.6$)$ & 0.13 \\
\hline $\mathrm{aVL}$ & 2.5 (1.4 to 4.4$)$ & 0.001 * & $2.6(1.1$ yo 6.2$)$ & 0.037 * \\
\hline $\mathrm{aVF}$ & 1.7 (0.98 to 2.9$)$ & 0.058 & $1.7(0.70$ to 4.0$)$ & 0.25 \\
\hline V1 & 1.9 (1.1 to 3.3$)$ & $0.016^{*}$ & $2.1(0.89$ to 5.1$)$ & 0.089 \\
\hline V2 & 2.3 (1.4 to 3.9 ) & $0.002^{*}$ & $1.8(0.74$ to 4.3$)$ & 0.19 \\
\hline V3 & 2.3 (1.3 to 3.9 ) & $0.003 *$ & 2.3 (0.95 to 5.7$)$ & 0.066 \\
\hline V4 & 3.1 (1.8 to 5.2$)$ & $<0.001 *$ & 2.5 (1.1 to 5.9 ) & $0.037^{*}$ \\
\hline V5 & 2.4 (1.4 to 4.0 ) & $0.001^{*}$ & 2.0 (0.84 to 4.7$)$ & 0.12 \\
\hline V6 & 2.9 (1.7 to 4.9$)$ & $<0.001$ * & 3.1 (1.3 to 7.3$)$ & $0.011^{*}$ \\
\hline Mean QTc & 2.2 (1.2 to 3.9$)$ & $0.009 *$ & $2.5(0.98$ to 6.2$)$ & 0.056 \\
\hline QTc max & 3.2 (1.9 to 5.4$)$ & $<0.001^{*}$ & 4.1 (1.7 to 9.8$)$ & $0.002 *$ \\
\hline QTc dispersion & $1.4(0.79$ to 2.3$)$ & 0.28 & 0.74 (0.27 to 2.0$)$ & 0.56 \\
\hline
\end{tabular}

(ICD-9 codes 410.0 to 414.9 , and 429.2 were used to define cardiac deaths).

\section{Statistical methods}

Statistical analysis was undertaken using SPSS for Windows. Univariate analyses (Cox regression) allowed us to test whether QTc of each lead as continuous variables predicted the primary end points.

Relative risks (RR) of having a prolonged QTc in all the leads of the ECG and the 95\% confidence intervals (CIs) were calculated using a Cox regression model (univariate analyses, upper third versus the others). The leads with prolonged QTc carrying the greatest relative risk of cardiac death were chosen along with QTC max for further evaluation. To allow for confounding effects, we included pulse pressure, glucose, cholesterol, and ischaemic heart disease (patient reporting a personal past history of myocardial infarction, angina, or coronary artery bypass grafting, or was using a nitrate) in the multivariate Cox regression models along with the QTc max or the QTc of the chosen leads.

The sensitivity and specificity of different cut off values of QTc length at the time of diagnosing cardiac death within five years after the cerebrovascular event were derived from receiver operator characteristic (ROC) curves. By way of comparison, ROC curves were also plotted with death from all causes as the end point.

Finally, Kaplan-Meier survival analysis compared the difference in cardiac mortality between patients with prolonged QTc and those with normal QTc.

\section{RESULTS}

We recruited 404 stroke survivors (192 women, 212 men). Their mean (SD) age was 68 (11.4) years (range 32-100 years). Mean blood pressure was 154.1 (24.2)/87.9 (13.2) $\mathrm{mm} \mathrm{Hg}$. Mean pulse pressure was 66.2 (19.7) $\mathrm{mm} \mathrm{Hg.}$ Forty four per cent of the cohort were non-smokers, $20 \%$ ex-smokers, and $36 \%$ current smokers; $18.1 \%$ were on aspirin, $4.7 \%$ were on dipyridamole.

There were 34 diabetic patients $(8.4 \%)$, but only $70.8 \%$ (259 of 366) had a random glucose of $<6 \mathrm{mmol} / \mathrm{l}$ at one year; 107 of $366(29 \%)$ had a random glucose $\geqslant 6 \mathrm{mmol} / \mathrm{l}$. Eighty two patients $(20.3 \%)$ were on diuretics at the time of the stroke. Only 3.2\% were on an angiotensin converting enzyme (ACE) inhibitor $(n=13)$ and $11.4 \%$ were on $\beta$ adrenergic blockers $(\mathrm{n}=46)$.

One hundred and nine patients (27\%) had overt ischaemic heart disease (that is, the patient reported a personal past history of myocardial infarction, angina, or coronary artery bypass grafting, or was using a nitrate).
Fifty six of the 404 patients died. Of these deaths, 21 $(37.5 \%)$ were cardiac ( 17 from ischaemic heart disease, three from hypertension, and one from other cardiac causes). There were 21 stroke deaths (37.5\%). Miscellaneous other causes accounted for the remaining deaths $(\mathrm{n}=14)$.

QTC max was associated with an increased risk of death from any cause and of cardiac death (table 1 and appendix, table 1 (see website for appendix tables)). There was a weak but significant relation between QTc max and some conventional risk factors for atherosclerosis such as pulse pressure (Spearman $r=0.11$, two tailed $\mathrm{p}=0.032)$, glucose $(r=0.17$, $\mathrm{p}=0.001)$, and cholesterol $(r=0.1 \mathrm{l}, \mathrm{p}=0.033)$ (appendix, table 2). However, even after adjusting for these potentially confounding risk factors and a past history of ischaemic heart disease, coronary artery bypass graft surgery, or nitrate use, QTc max was still significantly associated with an increased risk of cardiac death and of death from any cause.

Further, we found that the QTc measured from any single lead of the ECG except aVR predicted total mortality (table 1 and appendix, table 1) using a univariate model (Cox regression mortality analysis). Moreover, the QTc measured from most of the leads (except leads I, II, aVR, and aVF) significantly predicted cardiac death in univariate analyses.

Chest lead V6 and limb lead III were the leads in which a prolonged QTc carried the greatest risk of cardiac death (unadjusted RR $=3.1$ ) (table 1 ). Even after adjusting for pulse pressure, glucose, cholesterol, and known ischaemic heart disease, a prolonged QTc in those leads carried a threefold increase in the relative risk of predicting cardiac death (table 2 and appendix, table 3). When prolonged QTc was entered into the multivariate analyses, it carried at least as high a relative risk as the traditional measures of pulse pressure, glucose, cholesterol, and known ischaemic heart disease. For example, pulse pressure carried a 2.3-fold significant increase in the risk of cardiac death, while a long QTc in V6 carried a 2.8-fold increase (table 2).

When QTc of lead V6 was entered into a multivariate analysis, traditional measures of pulse pressure, glucose, cholesterol, and overt ischaemic heart disease became nonsignificant at predicting cardiac death (table 2). With death from all causes as the outcome measure, a long QTc in lead V6 was also associated with a higher relative risk (RR 2.9, 95\% CI 1.6 to $5.3 ; \mathrm{p}<0.001$ ) than any other variable in a multivariate Cox regression model taking into account pulse pressure, glucose, cholesterol, and overt ischaemic heart disease. By way of comparison, QTc max was associated with a threefold increase in the relative risk of cardiac death and a 2.5 -fold increase in the risk of death from any cause (appendix, table 4). 
Table 2 Multivariate analysis assessing the relative importance of QTc in lead V6 compared with other known cardiovascular risk factors

\begin{tabular}{|c|c|c|c|c|c|c|}
\hline \multirow[b]{2}{*}{ Covariates } & \multicolumn{3}{|c|}{ Death from all causes } & \multicolumn{3}{|c|}{ Cardiac death } \\
\hline & RR† & $95 \% \mathrm{Cl}$ & $p$ Value & RR† & $95 \% \mathrm{Cl}$ & $\mathrm{p}$ Value \\
\hline QTc V6 & 2.9 & 1.6 to 5.3 & $<0.001$ & 2.8 & 1.1 to 7.3 & 0.028 \\
\hline IHD & 2.0 & 1.1 to 3.5 & 0.028 & 1.8 & 0.68 to 4.6 & 0.24 \\
\hline Cholesterol & 0.9 & 0.48 to 1.6 & 0.7 & 0.92 & 0.36 to 2.4 & 0.86 \\
\hline Glucose & 1.1 & 0.62 to 2.1 & 0.7 & 1.5 & 0.59 to 3.9 & 0.39 \\
\hline Pulse pressure & 1.6 & 0.87 to 2.8 & 0.1 & 2.3 & 0.91 to 5.7 & 0.078 \\
\hline
\end{tabular}

†Upper third $v$ the rest, except IHD (which is either present or absent)

IHD, ischaemic heart disease (past history of angina, myocardial infarction, coronary artery bypass grafting,

or nitrate ingestion).

\begin{tabular}{|c|c|c|c|c|c|c|}
\hline \multirow[b]{2}{*}{$\begin{array}{l}\text { Cut off value } \\
(\geqslant)(\mathrm{ms})\end{array}$} & \multicolumn{2}{|c|}{$\begin{array}{l}12 \text { lead QTc max (area } \\
\text { under ROC curve }=0.71 \text {, } \\
S E=0.054 ; p=0.003 \text { ) }\end{array}$} & \multicolumn{2}{|c|}{$\begin{array}{l}\text { QTc measured from lead V6 } \\
\text { only (area under ROC } \\
\text { curve }=0.70, S E=0.057 \\
p=0.005 \text { ) }\end{array}$} & \multicolumn{2}{|c|}{$\begin{array}{l}\text { QTc measured from lead } \\
\text { III only (area under ROC } \\
\text { curve }=0.71, S E=0.069 ; \\
p=0.004 \text { ) }\end{array}$} \\
\hline & $\begin{array}{l}\text { Sensitivity } \\
\text { (\%) }\end{array}$ & $\begin{array}{l}\text { Specificity } \\
(\%)\end{array}$ & $\begin{array}{l}\text { Sensitivity } \\
\text { (\%) }\end{array}$ & $\begin{array}{l}\text { Specificity } \\
\text { (\%) }\end{array}$ & $\begin{array}{l}\text { Sensitivity } \\
\text { (\%) }\end{array}$ & $\begin{array}{l}\text { Specificity } \\
\text { (\%) }\end{array}$ \\
\hline 400 & 100 & 6 & 100 & 23 & 75 & 47 \\
\hline 410 & 100 & 19 & 85 & 39 & 65 & 62 \\
\hline 420 & 100 & 31 & 70 & 53 & 55 & 73 \\
\hline 430 & 90 & 40 & 65 & 64 & 45 & 86 \\
\hline 480 & 35 & 82 & 10 & 94 & 5 & 98 \\
\hline
\end{tabular}

Table 3 showed that a QTc of $\geqslant 430 \mathrm{~ms}$ in lead V6 had a sensitivity of $65 \%$ and a specificity of $64 \%$ for predicting cardiac death. However, if the QTc in V6 was $\geqslant 480 \mathrm{~ms}$, then the specificity for predicting cardiac death improved to $94 \%$. Clearly, different cut off values for V6 could be chosen, depending on whether the precise clinical situation required high sensitivity or high specificity (see Discussion).

Reproducibility or reliability was measured by comparing the QT parameters of 295 ECGs digitised twice by the same blinded individual on separate occasions. The $\alpha$ coefficient was used to assess intraobserver reproducibility; $\alpha$ was 0.89 for QTc max, 0.79 for QTc dispersion, and 0.92 for QTc V6. Thus it appeared that the QTc measured from lead V6 alone had a higher intraobserver reproducibility than the classic QTc dispersion and QTc max. Measurement of QTc in leads I, aVR, aVF, and V2-V6 had the highest $\alpha$ coefficient or reliability $(\geqslant 90 \%)$ (appendix, table 6). The QTc max occurred most often in leads V6 (14\%), I (12\%), V3 (11\%), and V5 (11\%),

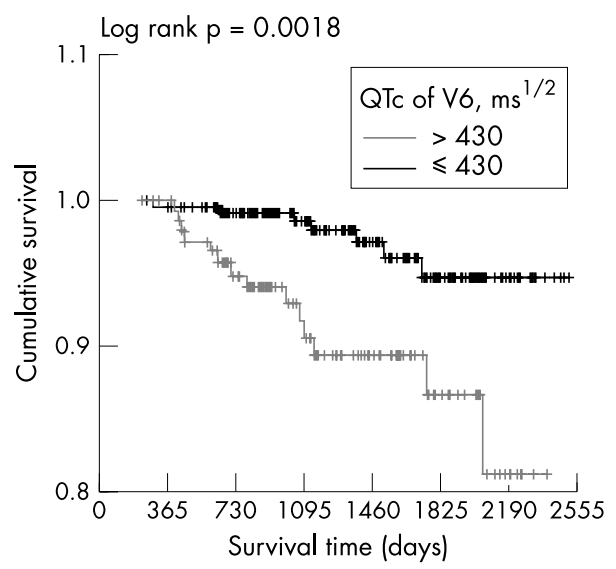

Figure 1 Kaplan-Meier curves showing a prolonged QTc of lead V6 was associated with cardiac death post-stroke. whereas QTc min occurred most often in leads Vl (39\%), III (14\%), and aVL(14\%). Clearly, omission of leads which contained the maximum or minimum QTc will lead to underestimation of QTc dispersion. This may be why QTc measurement in a single lead such as lead V6 was more reproducible.

Finally, Kaplan-Meier curves graphically displayed the association between a prolonged QTc in lead V6 and cardiac death $(\log$ rank $\mathrm{p}=0.0018)$ (fig 1$)$.

Demographic data (including mean and cut off values defining the upper third of QTc parameters and other variables) are shown in the appendix, table 7.

\section{DISCUSSION}

There were four main reasons for carrying out this study. First, a patient who makes a good recovery from a stroke is still at high risk of cardiac death. Second, despite their high incidence of cardiac death, the management of stroke patients focuses mainly on their neurological recovery, such that detailed cardiac investigations are seldom done unless the patient has specific cardiac symptoms or signs. Third, many stroke survivors are unlikely to be able to exercise enough to develop the hallmark symptoms of cardiac disease, such as chest pain or dyspnoea, so their absence may be falsely reassuring. Fourth, many stroke survivors are also unlikely to be able to undertake an exercise ECG test, which is the traditional way of risk stratifying cardiac patients for further investigations and treatment. Alternative approaches and novel thinking are therefore required to reduce cardiac deaths in stroke survivors.

A prolonged heart rate corrected QT interval is an independent predictor for cardiac and all cause mortality in older men and women. The risk associated with a prolonged QT is hardly affected by the heart rate correction formula used. ${ }^{12}$ QTc was a strong predictor of all cause mortality $(p<0.0001)$ and a significant though weaker predictor of cardiovascular mortality $(\mathrm{p}=0.016)$ in multivariate Cox regression analyses controlling for risk factors in the Strong heart study. It is unclear whether the difference is at least 
partly explained by the fact that there were more patients who died (of any cause) compared with cardiac deaths. In 1998, Elming and colleagues showed in a large Danish population that prolongation of the QT interval (mean of 12 leads greater than $430 \mathrm{~ms}$ ) was independently associated with a worse prognosis for cardiovascular mortality and morbidity than a QT interval of less than $360 \mathrm{~ms}^{2}{ }^{2}$ However, a careful study of the methodology shows that the QT interval was derived as a mean of 12 leads.

Methodological problems have hampered QT interval analysis, especially because of difficulty in identifying the end of the T wave. Such difficulties are magnified the more ECG leads need to be analysed. This makes our finding that the QTC measured from any single lead of the ECG (except aVR) predicted mortality particularly important.

\section{Clinical implications}

Our study shows that the QTc measured from any lead except aVR of the ECG did indeed predict total mortality following a stroke. Importantly, we found that a prolonged QTc in lead V6 carried a relative risk of 2.8 for predicting cardiac death (even after adjusting for pulse pressure, glucose, cholesterol and overt ischaemic heart disease). When QTc of lead V6 was entered into a multivariate analysis, those conventional measures became non-significant for predicting cardiac death. This suggests that QTc in lead V6 should be measured in all stroke survivors, in addition to the conventional risk factors in order to improve risk stratification.

This begs the question of why QTc identifies future cardiac risk over and above conventional risk factors. Is it possible that QTc is identifying subclinical cardiac disease which might be reversible if detected? In turn, this begs the question of which acquired cardiac diseases are actually associated with a prolonged QTc. The prevalence of QT interval prolongation is higher in people with diabetes and its complications. ${ }^{13}$ Current evidence suggests that long QT dispersion or a long QTc interval is associated with acquired coronary artery disease, ${ }^{14}{ }^{15}$ carotid intima-media thickness, ${ }^{16}$ left ventricular systolic dysfunction, ${ }^{17}$ left ventricular hypertrophy, ${ }^{18}$ and arrhythmias. ${ }^{19}$ Importantly, many of the above conditions are treatable-for example, the use of $\beta$ blockers in addition to ACE inhibitors in left ventricular dysfunction, ${ }^{20}$ or lowering the usual target blood pressure when there is left ventricular hypertrophy. ${ }^{21}$ In the high risk patients with concomitant silent coronary artery disease, one might argue the case for lower than usual target blood pressure or cholesterol levels. ${ }^{22}$ Tests need to be specific if they are invasive or if treatments with potentially unpleasant side effects may follow their use; by contrast, non-invasive tests such as echocardiography need to be as sensitive as possible, so that few abnormal cases will be missed. On this basis, one might propose that a QTc in lead V6 of $\geqslant 420 \mathrm{~ms}$ with $70 \%$ sensitivity should be used to identify candidates for non-invasive tests such as echocardiography, and for drug treatment if unsuspected left ventricular dysfunction or left ventricular hypertrophy is found. Invasive investigations such as cardiac catheterisation in this patient population have substantially increased risks and should perhaps be considered only in those with greatly prolonged QTc plus objective evidence of myocardial ischaemia, such as significant ST depression at low workload, or inducible ischaemia affecting large territories on myocardial perfusion scanning. Whether such a strategy will reduce cardiac deaths in stroke survivors cost effectively will require further research.

Cardiac autonomic neuropathy carries a poor prognosis in diabetic patients. There is certainly evidence linking cardiac autonomic neuropathy with QTc prolongation in diabetes. ${ }^{23}$ However, in 3042 patients with type 1 diabetes, QT dispersion was associated with ischaemic heart disease and with diastolic blood pressure but not with neuropathy. ${ }^{24} \mathrm{~A}$ careful study of that paper, however, shows that QT dispersion values were derived from the thoracic leads only. This could underestimate the true QT dispersion, as the true maximum or minimum QT may be found in the limb leads. Given the limitation of attempting to derive QT dispersion from six leads, it may still be possible that increased QT dispersion and increased QTc identify different pathologies. Future research should study prospectively what spectrum of cardiac abnormalities is present in patients with prolonged QTc by performing a wide range of non-invasive cardiac tests on each patient (such as echocardiography for left ventricular dysfunction and hypertrophy, treadmill exercise tests or myocardial perfusion scanning, and ambulatory ECG monitoring for arrhythmias and heart rate variability). There is some evidence in diabetic patients that the greater the number of cardiac abnormalities, the more prolonged the QT dispersion..$^{25}$ There is as yet no report showing whether prolongation of QTC max or QTC derived from a single lead in stroke survivors reflects an increased burden of asymptomatic cardiac abnormalities, as indicated by an increased number of reversible conditions. Thus the finding that QTc prolongation was associated with cardiac death is interesting, and future research should concentrate on exploring the underlying reasons for this intriguing association.

\section{Conclusions}

We have shown that the QTc measured from any lead except aVR on the ECG predicted mortality following a stroke. QTc measured from V6 had comparable prognostic value to the QTc max derived from measurement of QTc from all 12 leads of the ECG. The fact that a prolonged QTc in lead V6 carried a threefold increase in the relative risk of cardiac death-even after adjusting for overt ischaemic heart disease, pulse pressure, glucose, and cholesterol-suggests that patients with a prolonged QTC in lead V6 are at high risk of suffering a cardiac death and may need more intensive investigations and treatments than are currently routine practice. Thus the measurement of QTc in lead V6 appears to be a time efficient way of risk stratifying stroke survivors for intensified investigations and treatment to help prevent impending cardiac death.

\section{ACKNOWLEDGEMENTS}

We thank S Kendrick and the ISD, National Health Service, Edinburgh, for providing mortality data; Helen Brewster and Wendy Cassels who collected data in this study; and Valerie Bruce who entered the data. The study was supported by a grant from the Chief Scientist Office (Scottish Office) and by Tayside Health Board, Tayside University Hospitals NHS Trust, Tayside Primary Care NHS Trust and University of Dundee. KYKW is supported by the British Heart Foundation.

There were no conflicts of interest.

\section{Authors' affiliations}

K Y K Wong, A D Struthers, The Cardiovascular Research Group, Department of Clinical Pharmacology and Therapeutics, University of Dundee Medical School, Ninewells Hospital, Dundee, UK R S Mac Walter, D Douglas, H W Fraser, Stroke Studies Centre, Department of Medicine, University of Dundee Medical School S A Ogston, Department of Epidemiology and Public Health, University of Dundee Medical School

\section{REFERENCES}

1 Dennis MS, Burn JP, Sandercock PA, et al. Long-term survival afte first-ever stroke: the Oxfordshire Community Stroke Project. Stroke 1993:24:796-800.

2 Elming $\mathbf{H}$, Holm E, Jun $L$, et al. The prognostic value of the QT interva and QT interval dispersion in all-cause and cardiac mortality and morbidity in a population of Danish citizens. Eur Heart J 1998; 19:1391-400.

3 de Bruyne MC, Hoes AW, Kors JA, et al. QTc dispersion predicts cardiac mortality in the elderly: the Rotterdam Study. Circulation 1998;97:467-72. 
4 Okin PM, Devereux RB, Howard BV, et al. Assessment of QT interval and QT dispersion for prediction of all-cause and cardiovascular mortality in American Indians: the Strong Heart Study. Circulation 2000;101:61-6.

5 Barr CS, Naas A, Freeman M, et al. QT dispersion and sudden unexpected death in chronic heart failure. Lancet 1994;343:327-9.

6 Darbar D, Luck J, Davidson N, et al. Sensitivity and specificity of QTC dispersion for identification of risk of cardiac death in patients with peripheral vascular disease. BM 1996;312:874-8.

7 Fei L, Goldman JH, Prasad K, et al. QT dispersion and RR variations on 12-lead ECGs in patients with congestive heart failure secondary to idiopathic dilated cardiomyopathy. Eur Heart J 1996;1 17:258-63.

8 Naas AA, Davidson NC, Thompson C, et al. QT and QTc dispersion are accurate predictors of cardiac death in newly diagnosed non-insulin dependent diabetes: cohort study. BM 1998;316:745-6.

9 Murray A, McLaughlin NB, Campbell RW. Measuring QT dispersion: man versus machine. Heart 1997;77:539-42.

10 MacWalter RS, Coid DR, Fraser HW, et al. The Dundee stroke register: experience of the first ten years. Scot Med J 1999;44:103-5.

11 Macintyre K, Stewart S, Chalmers J, et al. Relation between socioeconomic deprivation and death from a first myocardial infarction in Scotland: population based analysis. BM 2001;322:1152-3.

12 de Bruyne MC, Hoes AW, Kors JA, et al. Prolonged QT interval predicts cardiac and all-cause mortality in the elderly. The Rotterdam study. Eur Heart J 1999:20:278-84.

13 Veglio $M$, Borra $M$, Stevens LK, et al. The relation between QTc interval prolongation and diabetic complications. The EURODIAB IDDM complication study group. Diabetologia 1999;42:68-75.

14 Moreno FL, Villanueva T, Karagounis LA, et al. Reduction in QT interval dispersion by successful thrombolytic therapy in acute myocardial infarction. TEAM-2 study investigators. Circulation 1994;90:94-100.

15 Sporton SC, Taggart P, Sutton PM, et al. Acute ischaemia: a dynamic influence on QT dispersion. Lancet 1997;349:306-9.

16 Festa A, D'Agostino R, Rautaharju P, et al. Is QT interval a marker of subclinical atherosclerosis in nondiabetic subjects? The insulin resistance atherosclerosis study (IRAS). Stroke 1999;30:1566-71.
17 Davey P. QT interval lengthening in cardiac disease relates more to left ventricular systolic dysfunction than to autonomic function. Eur J Heart Failure 2000;2:265-71

18 Clarkson PB, Naas AA, McMahon A, et al. QT dispersion in essential hypertension. QIM 1995;88:327-32.

19 Pye M, Quinn AC, Cobbe SM. QT interval dispersion: a non-invasive marker of susceptibility to arrhythmia in patients with sustained ventricular arrhythmias? Br Heart J 1994;71:511-14.

20 CIBIS Investigators. The cardiac insufficiency bisoprolol study II (CIBIS-II): a randomised trial. Lancet 1999;353:9-13.

21 Verdecchia P, Schillaci G, Borgioni C, et al. Prognostic significance of serial changes in left ventricular mass in essential hypertension. Circulation 1998;97:48-54.

22 Pitt B, Waters D, Brown WV, et al. Aggressive lipid-lowering therapy compared with angioplasty in stable coronary artery disease. Atorvastatin versus revascularization treatment investigators. $N$ Engl J Med 1999;341:70-6.

23 Jermendy G, Toth $L$, Voros $\mathrm{P}$, et al. Cardiac autonomic neuropathy and QT interval length. A follow-up study in diabetic patients. Acta Cardiol 1991;46:189-200.

24 Veglio M, Giunti S, Stevens LK, et al. Prevalence of Q-T interval dispersion in type 1 diabetes and its relation with cardiac ischemia: the EURODIAB IDDM complications study group. Diabetes Care 2002;25:702-7.

25 Rana BS, Band M, Ogston SA, et al. Relation of QT dispersion to the number of different cardiac abnormalities in diabetes mellitus. Am J Cardiology (in press).

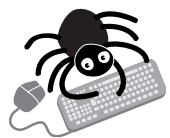

To see appendix tables 1-7 go to the Heart website-www.heartinl.com/supplemental

\section{IMAGES IN CARDIOLOGY}

\section{Prolonged cardiac arrest caused by glossopharyngeal neuralgia}

A 56 year old woman was referred to our hospital because of syncope during attacks of pain in the right side of her pharynx. She had a one year history of right glossopharyngeal neuralgia. Carbamazepine ( $200 \mathrm{mg}$ daily) relieved the pain for about eight months, but as time went on, it became less effective and completely failed to control an exacerbation of the pain four months before admission. During neuralgia, ECG monitoring revealed asystole up to 26 seconds (upper panel) with syncope and seizures. Although the dose of carbamazepine was increased up to $400 \mathrm{mg}$ daily, she continued to have spontaneous attacks of neuralgia and syncope associated with bradycardia and asystole. Therefore, a temporary cardiac pacemaker was needed to prevent syncopes before surgery. During the operation, right retromastoid craniectomy disclosed adhesions of the posterior inferior cerebellar artery (PICA) loop between cranial nerves IX and X (lower panel). Microvascular decompression was performed, followed by removal of the adhesions and freeing of the artery from these nerves. After the operation, the electrophysiologic study, carotid sinus massage, and head-up tilt testing showed no abnormal findings. No episodes of syncope or neuralgia occurred during a two month follow up postoperatively.

Glossopharyngeal neuralgia is an uncommon form of pain, but is well known as a cause of neurally mediated syncope. The afferent glossopharyngeal stimulus induces a vasovagal reflex, which causes bradycardia, cardiac arrest, and hypotension. In cases that are refractory to medical treatment, including carbamazepine, surgical treatment can relieve neuralgia and prevent syncope.

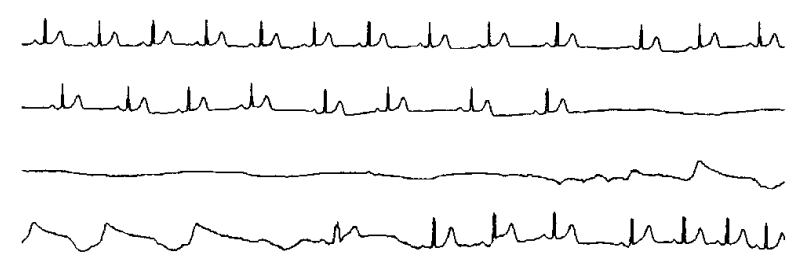

$1 \mathrm{mV}: 2.4 \mathrm{~mm}$

$1 \min$

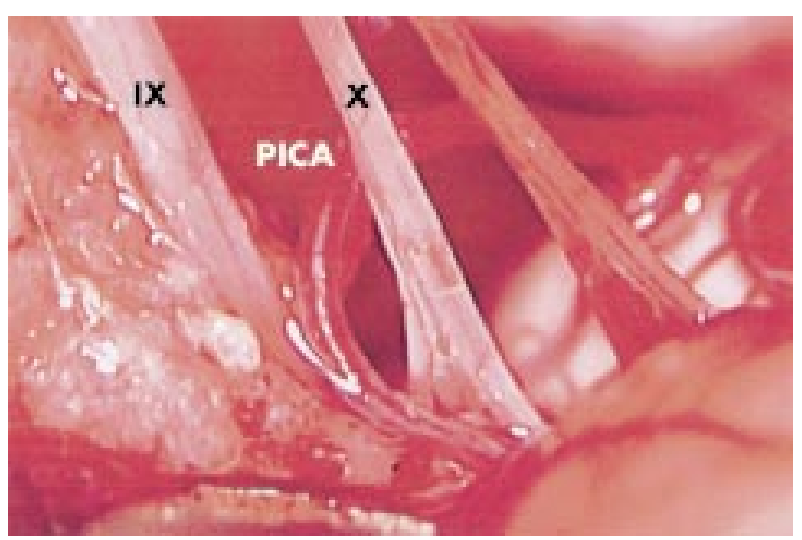

N Takaya 


\title{
SCIENTIFIC LETTER
}

\section{The variation of plasma concentrations of a novel, adipocyte derived protein, adiponectin, in patients with acute myocardial infarction}

\author{
S Kojima, T Funahashi, T Sakamoto, S Miyamoto, H Soejima, J Hokamaki, I Kajiwara, \\ S Sugiyama, M Yoshimura, K Fujimoto, Y Miyao, H Suefuji, A Kitagawa, N Ouchi, \\ S Kihara, Y Matsuzawa, H Ogawa
}

A diponectin is a new member of adipocyte derived proteins belonging to the soluble defence collagens. ${ }^{1}$ Plasma adiponectin concentrations in obese subjects are decreased in spite of an adipose specific expression. ${ }^{1}$ More interestingly, the patients with chronic coronary artery disease exhibited lower plasma adiponectin concentrations compared to body mass index (BMI) matched control subjects. ${ }^{2}$ On the other hand, adiponectin accumulates in the vascular subendothelial space when the endothelial barrier is damaged. ${ }^{3}$ In vitro, adiponectin suppresses the expression of adhesion molecules in the vascular endothelial cells and cytokine production from macrophages. ${ }^{24}$ Therefore, the molecule may be involved in the inflammation and tissue repairing processes.

Acute coronary syndrome is often precipitated by acute thrombosis. ${ }^{5}$ It is commonly accepted that the rupture or the erosion of plaques by the inflammatory process leads to coronary thrombosis and acute myocardial infarction (AMI). The $\mathrm{C}$ reactive protein (CRP) concentrations in the acute phase are suggested to reflect pre-existing coronary plaque instability associated with the onset of AMI. The significance of adiponectin in acute coronary syndrome has never been investigated. In the present study, we examined the serial change in plasma adiponectin concentrations and its relation to plasma CRP concentration in patients with AMI.

\section{METHODS}

Thirty four consecutive patients with AMI, who were admitted within six hours after the onset of symptoms, were included in this study. They underwent emergency coronary angiography for coronary thrombolytic treatment with recombinant tissue type plasminogen activator, percutaneous transluminal coronary angioplasty, and/or coronary stent placement immediately after they were diagnosed as having AMI. The successful recanalisation of the infarct related artery was achieved in all AMI patients. The control group consisted of 35 subjects who had atypical chest pain at rest, or with some exercise, but had no significant coronary artery stenosis $(<25 \%$ of luminal diameter) and no coronary spasm. The control group was selected from patients undergoing elective cardiac catheterisation, who had been matched for age, sex, and BMI with the AMI group. The criterion for exclusion in this study was the presence of inflammatory diseases (that is, collagen disease, advanced liver disease, malignant disease, septicaemia, arthritis, or other inflammatory or infectious diseases), except for ischemic heart disease.

In the patients with AMI, blood samples were obtained immediately after admission to measure plasma adiponectin and CRP concentrations. Venous blood samples were also taken in the same manner on days 3 and 7 and at four weeks after admission, from the antecubital vein early in the morning, to measure the plasma concentration of adiponectin. In the control subjects, blood samples were obtained at coronary angiography for plasma adiponectin and CRP concentrations, and other biochemical assessment. Plasma adiponectin concentrations were determined by enzyme linked immunosorbent assay. Plasma CRP concentrations were measured with a clinically validated high sensitivity assay (DadeBehring, Marburg, Germany).

\section{RESULTS}

There were no significant differences between the two groups in regard to the following variables: age, sex, the presence of hypertension, diabetes mellitus, smoking habit, BMI, serum total cholesterol concentration. Plasma adiponectin concentrations in the patients with AMI on admission (8.1 (4.8) $\mu \mathrm{g} /$ $\mathrm{ml}$ ) were significantly lower than those in the control subjects (10.9 (5.5) $\mu \mathrm{g} / \mathrm{ml}, \mathrm{p}=0.04)$. Plasma CRP concentrations in the patients with AMI on admission were higher than those in the controls $(0.14(0.12) \mathrm{mg} / \mathrm{dl} v 0.05(0.07) \mathrm{mg} / \mathrm{dl}, \mathrm{p}=0.01)$.

We studied the sequential changes of plasma adiponectin concentrations after admission in the patients with AMI. The plasma adiponectin concentrations declined significantly at 24 hours (6.2 (3.6) $\mu \mathrm{g} / \mathrm{ml}, \mathrm{p}=0.004)$ and at 72 hours $(5.8$ (3.4) $\mu \mathrm{g} / \mathrm{ml}, \mathrm{p}=0.0001$ ) compared to the concentrations on admission. Then, they nearly returned to the concentration on admission on day $7(7.5(4.1) \mu \mathrm{g} / \mathrm{ml})$ and at four weeks $(7.2$ (4.1) $\mu \mathrm{g} / \mathrm{ml}$ ) after the onset of AMI, but did not reach the concentration on admission (fig lA). We also examined the relation between plasma CRP concentrations on admission and the reduction of plasma adiponectin concentration at four weeks from the concentration on admission. The reduction of plasma adiponectin was closely correlated with plasma CRP concentrations on admission (fig 1B).

\section{DISCUSSION}

The precise mechanism of the decreased plasma adiponectin concentrations immediately after the onset of AMI remains unclear. Plasma adiponectin concentrations may decrease as the result of the rupture of coronary plaques. Adiponectin is detected in the injured vessels but not in the intact vascular walls in humans and rodents. ${ }^{34}$ It is possible that adiponectin targets the ruptured plaques resulting in their consumption in the circulating plasma. An alternative explanation is that the inflammatory process may be accelerated in subjects with low plasma adiponectin before the onset of AMI. The process has been believed to facilitate the rupture of the atherosclerotic plaques leading to coronary thrombosis. Active inflammation

Abbreviations: $\mathrm{AMI}$, acute myocardial infarction; $\mathrm{BMI}$, body mass index; CRP, $C$ reactive protein; TNF $\alpha$, tumour necrosis factor $\alpha$ 


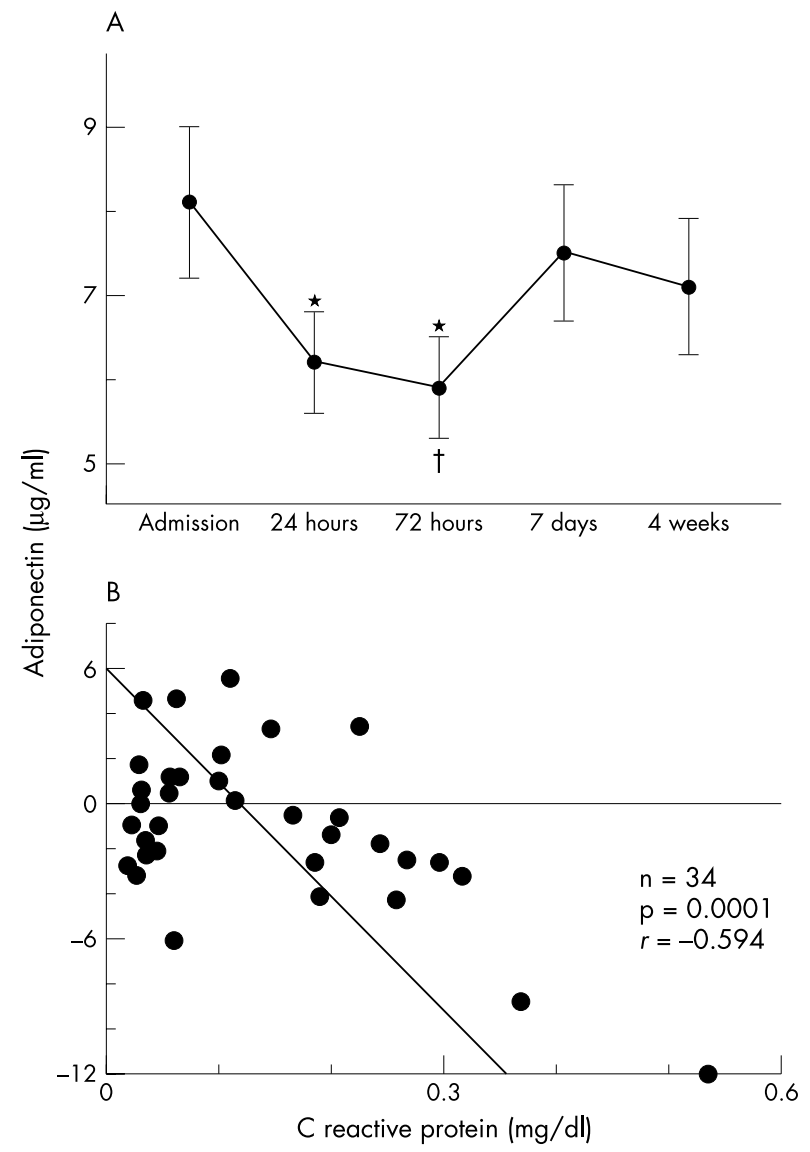

Figure 1 (A) Plot of time course of plasma adiponectin concentrations. Values are expressed as mean (SEM). ${ }^{*} p<0.01$ compared with values on admission; $\dagger p<0.05$ compared with values at seven days. (B) Correlation between the plasma $\mathrm{C}$ reactive protein concentration on admission and the reduction of plasma adiponectin concentration at four weeks after the onset of acute myocardial infarction from the concentration on admission.

and accumulation of activated monocyte derived macrophages secreting cytokines, chemokines, growth regulating molecules, and metalloproteinases were observed at the site of coronary plaque rupture in acute coronary syndrome. ${ }^{5}$ Adiponectin inhibits the expression of vascular cell adhesion molecule-1, endothelial leucocyte adhesion molecule-1, and intracellular adhesion molecule-1, which are detected in human atherosclerotic lesions, through the inactivation of tumour necrosis factor $\alpha(\mathrm{TNF} \alpha)^{2}$. Adiponectin also suppresses the activity of human monocyte macrophages including TNF $\alpha$ production and foam cell formation. ${ }^{4}$ Therefore, adiponectin may play some role in an inflammatory process in vascular walls.

The reduction of plasma adiponectin during the course of myocardial infarction significantly correlated with the plasma CRP concentrations immediately after the onset of AMI. The strong inflammatory activity in the coronary vulnerable plaque may induce the reduction of plasma adiponectin. The decrease of plasma adiponectin concentration will accelerate the inflammatory process, resulting in a vicious cycle.

\section{Authors' affiliations}

S Kojima, T Sakamoto, S Miyamoto, H Soejima, J Hokamaki, I Kajiwara, S Sugiyama, M Yoshimura, H Ogawa, Department of Cardiovascular Medicine, Kumamoto University School of Medicine, Kumamoto, Japan

A Kitagawa, Department of Pharmacy, Kumamoto University School of Medicine, Kumamoto, Japan

K Fujimoto, Y Miyao, H Suefuii, Department of Cardiovascular Medicine, Kumamoto National Hospital, Kumamoto, Japan T Funahashi, N Ouchi, S Kihara, Y Matsuzawa, Department of Internal Medicine and Molecular Science, Graduate School of Medicine, Osaka University, Suita, Osaka, Japan

Correspondence to: Dr Hisao Ogawa, Department of Cardiovascula Medicine, Kumamoto University School of Medicine, 1-1-1 Honjo,

Kumamoto City, 860-8556 Japan; ogawah@kumamoto-u.ac.jp

\section{REFERENCES}

1 Arita Y, Kihara S, Ouchi N, et al. Paradoxical decrease of an adipose-specific protein, adiponectin, in obesity. Biochem Biophys Res Commun 1999;257:79-83.

2 Ouchi N, Kihra S, Arita Y, et al. Novel modulator for endothelial adhesion molecules: adipocyte-derived plasma protein adiponectin. Circulation 1999;100:2473-6.

3 Okamaoto Y, Arita Y, Nishida M, et al. An adipocyte-derived plasma protein, adiponectin, adheres to injured vascular walls. Horm Metab Res 2000;32:47-50.

4 Ouchi N, Kihara S, Arita Y, et al. Adipocyte-derived plasma protein, adiponectin, suppresses lipid accumulation and class $A$ scavenger receptor expression in human monocyte-derived macrophages. Circulation 2001;103:1057-63.

5 Ross R. Atherosclerosis - an inflammatory disease. N Engl J Med 1999;340:115-26.

\section{ERRATUM}

Wong KY, et al. Long QTc predicts future cardiac death in stroke survivors. Heart 2003;89:377-81.

The second co-author's name is MacWalter RS, not Mac Walter RS. 